\title{
Una justicia en salida. Novedades procesales del M.P. Mitis iudex dominus Iesus
}

\author{
Marcelo Gidi \\ FACULTAD DE TEOLOGÍA \\ PONTIFICIA UNIVERSIDAD CATÓLICA DE CHILE \\ mgidi@uc.cl
}

Resumen: Haciéndose cargo de la dramática situación en la que viven muchos cristianos, Francisco ha promulgado una nueva ley para los procesos de nulidad matrimonial. Una reforma procesal que reivindica las propiedades esenciales del matrimonio y hace más cercana y ágil la justicia eclesiástica. Nueva legislación que da cuenta de los principios teológicos del matrimonio y en donde se hace una explícita referencia al rol del Obispo en la administración de justicia matrimonial en el contexto de la pastoral familiar de la diócesis.

Palabras clave: Obispo, proceso, más breve, nulidad, matrimonio.

Abstract: Considering the dramatic situations many Christians live, Pope Francis has enacted a new law for marriage annulment processes. A procedural reform which claims the essential properties of marriage and makes ecclesiastical justice more accesible and agile. The new legislation considers the theological principles of marriage and makes an explicit reference to the role of the Bishop in the administration of justice in the context of the diocesan ministry to the family.

Key words: Bishop, process, briefer, annulment, marriage. 


\section{INTRODUCCIÓN}

La experiencia del fracaso matrimonial es siempre dolorosa ${ }^{1}$. Este mismo fracaso, por otro lado, puede convertirse en una oportunidad para la reflexión y la renovación. Afirma Francisco:

"Sueño con una opción misionera capaz de transformarlo todo [...] La reforma de estructuras que exige la conversión pastoral solo puede entenderse en este sentido: procurar que todas ellas se vuelvan más misioneras, que la pastoral ordinaria en todas sus instancias sea más expansiva y abierta, que coloque a los agentes pastorales en constante actitud de salida y favorezca así la respuesta positiva de todos aquellos a quienes Jesús convoca a su amistad" (EG 27)22.

Con conciencia de la propia responsabilidad el Papa Francisco, el 8 de septiembre de 2015, promulgó la ley que contiene el nuevo proceso de declaración de nulidad matrimonial ${ }^{3}$. No se hacía en materia procesal matrimonial una reforma de esta envergadura desde el siglo XVIII ${ }^{4}$. Con la entrada en vigencia del motu proprio Mitis Iudex Dominus Iesus [MIDI], que reforma el Código de derecho canónico de la Iglesia latina en los cann. 1671-1691, se puede perfectamente hablar de una refundación del proceso matrimonial canónico que responde máximamente al deseo del legislador de una conversión de la Iglesia.

A la luz de la "hermenéutica sinodal"', que la Iglesia se vuelva hacia sus hijos marcados por el amor herido y perdido, a quienes es necesario

1 Como se indica expresamente en el Proemio del MIDI: "alimenta este impulso reformador el enorme número de fieles que, aun deseando proveer a su propia conciencia, con demasiada frecuencia quedan apartados de las estructuras jurídicas de la Iglesia debido a la distancia física o moral”.

2 FRANCISCO, Exh. Apost. Evangelii Gaudium, en https://w2.vatican.va/content/francesco/es/apost_exhortations/documents/papa-francesco_esortazione-ap_20131124_ evangelii-gaudium.html (consultada 10-08-2016)

3 De fecha 15 de agosto de 2015-publicado el pasado 8 de septiembre y en vigor desde el 8 de diciembre de 2015. El cual no tendrá efectos retroactivos. Sin embargo, en el caso de un proceso ya en curso cuya sentencia de nulidad se falle y notifique después del 8 de diciembre, se aplicarán los efectos de la reforma.

4 Bendicto XVI, Constitución Dei Miseratione del 3 noviembre 1742, en Bullarium, I, Romae 1746,

5 Se lee en la Exh. Post. Amoris laetitia: "El camino sinodal permitió poner sobre la mesa la situación de las familias en el mundo actual, ampliar nuestra mirada y reavivar nuestra conciencia sobre la importancia del matrimonio y la familia. Al mismo tiempo, la complejidad de los temas planteados nos mostró la necesidad de 
volver a donar confianza y esperanza, Francisco le pide a la Iglesia conversión personal y estructural en la administración de justicia. Lo anterior comporta una serie de desafíos normativos. Esta propuesta pontificia es una de las claves de lectura de la reforma inaugurada hace un año por el MIDI ${ }^{6}$. Reforma que ha suscitado, no podemos negarlo, mucha duda, confusión e incertidumbre a las cuales solo la doctrina, la practica judicial y los respectivos organismos competentes de la Santa Sede, podrán ir respondiendo para que la nueva normativa logre la claridad y precisión necesaria a toda ley ${ }^{7}$.

Como ha afirmado recientemente Francisco, "es importante que la nueva normativa sea recibida y profundizada, en el mérito y en el espíritu, especialmente por los operadores de los tribunales eclesiásticos, con el fin de ofrecer un servicio de justicia y caridad a las familias"8. La finalidad de este artículo, centrada en un estudio analítico-exegético del MIDI, es contribuir a que MIDI sea comprendido, acogido, profundizado y utilizado, en el contenido y en su espíritu, del modo más adecuado y eficaz posible. En estas líneas me limitaré a analizar algunas de las muchas cuestiones que señala y establece la dinámica renovadora

seguir profundizando con libertad algunas cuestiones doctrinales, morales, espirituales y pastorales", n.2, en http://w2.vatican.va/content/francesco/es/apost_exhortations/documents/papa-francesco_esortazione-ap_20160319_amoris-laetitia.html (Consultada15-09-2016).

6 Afirma Francisco, que "Las leyes que ahora entran en vigor quieren mostrar la cercanía de la Iglesia a las familias heridas, con el deseo de que a la multitud de los que viven el drama del fracaso conyugal llegue la obra sanadora de Cristo, a través de las estructuras eclesiales, con la esperanza de que ellos se descubran nuevos misioneros de la misericordia de Dios para los demás hermanos, en beneficio de la institución familiar”, Rescripto “ex audientia”, 7 diciembre 2015, en https://w2.vatican.va/ content/francesco/es/letters/2015/documents/papa-francesco_20151207_rescrittoprocesso-matrimoniale.html (consultado 15-03-2016)

7 Coccopalmeiro, Discurso durante la Presentación de la Nueva Ley, Conferenza Stampa di presentazione delle due Lettere "motu proprio datae" di Papa Francesco "Mitis Iudex Dominus Iesus" e "Mitis et misericors Iesus", sulla riforma del processo canonico per le cause di dichiarazione di nullità del matrimonio, rispettivamente nel Codice di Diritto Canonico e nel Codice dei Canoni delle Chiese Orientali, 08.09.2015, en http://press.vatican.va/content/salastampa/it/ bollettino/pubblico/2015/09/08/0654/01439.html\#cocc (consultado 17-05-2016)

8 Francisco, Discurso a los participantes en un curso organizado por el Tribunal de la Rota Romana, 12 marzo 2016, en https:/w2.vatican.va/content/francesco/es/ speeches/2016/march/documents/papa-francesco_20160312_corso-rota-romana. html (consultado 18-5-2016) 
de MIDI. Específicamente se ofrecen criterios que pueden ayudar a entender y aplicar no solo los nuevos cánones sino también comprender sus principios inspiradores. Sin pretensión de exhaustividad vamos a dedicar nuestra reflexión a los siguientes puntos:

A. Un primer aspecto trata de algunas breves reflexiones acerca la estructura y naturaleza del MIDI y a la vigencia o no de la Instrucción Dignitas Connubii (DC).

B. Un segundo aspecto analizará algunos de los criterios guías de la reforma del proceso judicial canónico según el Proemio del MIDI.

A. a) la estrucutra y naturaleza

La técnica legislativa utilizada en la redacción de este Motu proprio MIDI, no puede sino ser considerada inusual, y si se me permite, imprecisa desde la perspectiva de la técnica jurídica de redacción de documentos legislativos. Lo anterior, entre otros motivos, por su texto, por su contenido, por su estructura tripartita y por la relación del MIDI con otras leyes eclesiásticas en vigor hasta el 8 de diciembre 2015, especialmente la DC. Recordamos que MIDI está estructurado en tres partes: proemio, cánones y reglas procesales.

El Proemio, que contiene "fundamentalia criteria quae opus reformationis rexerunt", parte expositiva de los motivos de la reforma y que enumera los "criterios fundamentales en que se apoya, contiene no solo la explicación de la finalidad y el espíritu de MIDI, sino además, la indicación de los criterios básicos de interpretación de la misma. Frecuentemente para entender un canon o una regla de procedimiento, será necesario recurrir a estos criterios ${ }^{9}$;

Un conjunto de Cánones que sustituyen por completo parte de las disposiciones del Libro VII, Parte III, Capítulo I del CICI/83, específi-

9 La Relación Final del Sínodo de los Obispos al Santo Padre (24-10-2015) afirma en su n.82: "Los Motu Proprio recientes Mitis Iudex Dominus Iesus y Mitis et Misericors Iesus han llevado a una simplificación de los procedimientos para una eventual declaración de nulidad matrimonial", en http://www.vatican.va/roman_ curia/synod/documents/rc_synod_doc_20151026_relazione-finale-xiv-assemblea_ sp.html (consultado 10-05-2016) 
camente han sido abrogados los cann. $1671-1691^{10}$ y que forman parte del CIC/83; y

Las Reglas procesales adjuntas (RP), una curiosa singularidad formal de la norma, que son consideradas por el legislador "necesarias para una correcta y esmerada aplicación de la ley renovada" (arts. 1-21) ${ }^{11}$.

Los nuevos cánones (cann.1671-1691), deberían ser el tema central del MIDI, especialmente porque reforma el Código de Derecho canónico (CIC) y simplemente recibir encuadre interpretativo gracias al Proemium y una mejor concreción y segura aplicación con las RP. Pero no ha sido así. Se ha pretendido hacer algo más que solamente reformar los cánones del CIC.

De hecho la estructura del MIDI es variada y compleja. Las tres partes del MIDI, han sido publicadas contemporáneamente como parte de un mismo acto pontificio y por la modalidad y fórmula de aprobación, están contenidas en único acto y documento. Lo anterior me lleva a considerar al MIDI como un complejo normativo unitario que desde el punto de vista de la ciencia canónica, siempre en cuanto acto pontificio, posee una naturaleza jurídica distinta según sea la parte del documento que se trate: una propia y específica naturaleza jurídica considerada desde la teoría de las fuentes del derecho.

10 En esta línea afirma el mismo Papa en MIDI, que “...decreto y establezco que el Libro VII del Código de Derecho Canónico, Parte III, Título I, Capítulo I sobre las causas para la declaración de nulidad del matrimonio (cánones 1671-1691), a partir del día 8 de diciembre de 2015, sea integralmente sustituido”, es decir son abrogadas. Pero debemos también señalar que en no pocos casos hay repeticiones de los cánones antiguos -cambiándolos de ubicación o de numeración- los que resultan ser idénticos a los que ya se contenían en los 21 cánones que ahora cesan. He detectado nada menos que doce coincidencias literales de cánones o parágrafos enteros de cánones.

11 Al final de los cánones reformados, agrega el Pontífice: "Al presente documento se unen reglas de procedimiento, que he considerado necesarias para la correcta y esmerada aplicación de la ley renovada, que debe observarse diligentemente, para la tutela del bien de los fieles [...], reglas que no pretenden exponer minuciosamente el conjunto de todo el proceso, sino sobre todo aclarar las principales innovaciones legislativas y, donde sea necesario, integrarlas." 
A. b) vigencia de la dignitas connubii (DC)

El can. $1691 \$ 3$, último canon de MIDI, establece que "En las demás cosas que se refieren al procedimiento, si no lo impide la naturaleza del asunto, aplíquense los cánones sobre los juicios en general y sobre el juicio contencioso ordinario, cumpliendo las normas especiales para las causas acerca del estado de las personas y para aquellas que se refieren al bien público" y el art. 6 de las RP, en relación al canon recién señalado, establece que "las presentes reglas no pretenden exponer minuciosamente el conjunto de todo el proceso...". Por las muchas dudas e incertidumbres que se manifestaron a nivel de la doctrina y de los Tribunales acerca la vigencia de otra normativa eclesiástica en materia, el 7 de diciembre 2015, afirmaba el mismo legislador en el Rescripto "ex audientia" que las leyes de reforma del proceso matrimonial más arriba citadas abrogan o derogan cualquier ley o norma contraria hasta ahora vigente, general, particular o especial, eventualmente aprobada también en forma específica".

A la luz de todas estas afirmaciones ¿Podemos los operadores de justicia seguir utilizando en el desarrollo de los procesos de nulidad matrimonial la DC? ¿La misma Instrucción ha sido abrogada o derogada?

Es evidente que la DC ha sido abrogada a la luz de lo establecido en el can. $34 \$ 3$ en aquellas materias que han sido totalmente reordenadas. Pero en línea, también, con los principios de derogación o abrogación establecidos en el CIC, podemos señalar que a tenor de los cann. 20 y 34 $\$ 3$, no ha habido por parte de MIDI una reordenación integral y completa de toda la materia de la ley precedente, única condición para que una ley posterior abrogue una anterior de igual alcance (universal en este caso), ni tampoco se ha dejado sin efecto toda la legislación matrimonial a la cual se refiere la DC, solo los cann. 1671-1691 (art.6). Es un hecho que MIDI no ha abrogado todo el CIC/83, sino solo en aquello que se refiere al proceso especial de nulidad matrimonial, tan solo 21 cánones. En este sentido lo establecido en el can.1691 \$3, cobra especial relevancia a tenor del can. $21^{12}$.

12 En caso de duda, no se presume en Derecho canónico la revocación de la ley precedente, sino que las leyes posteriores han de compararse y, en la medida de lo posible, conciliarse con las anteriores, can. 21. 
Afirmamos que en general los artículos de la DC han sido derogados, pero en particular, en aquellos otros artículos de la DC que estaban en relación directa o indirecta con los cánones abrogados del CIC, es decir los cann. 1671-1691, ha habido una abrogación. Para la aplicación correcta, segura, veloz y esmerada de todo el MIDI, será necesario utilizar un sistema de aplicación jerarquizada de las normas, de las particulares a las generales, recurriendo no solo al resto del CIC/83, sino también a la DC. Nos apoyamos en lo que establece el can. $34 \$ 3$ : "Las instrucciones dejan de tener fuerza, no solo por revocación explícita o implícita de la autoridad competente que las emitió, o de su superior, sino también al cesar la ley para cuya aclaración o ejecución hubieran sido dadas".

Por lo mismo, según el art. 6, "las presentes reglas no pretenden exponer minuciosamente el conjunto de todo el proceso", ni la MIDI regular todos los aspectos del proceso de nulidad del matrimonio, can. $1691 \$ 3$, se hace necesario, no obstante la nueva ley, recurrir todavía a la DC, mientras no se oponga a la nueva regulación y siempre subordinadamente a lo establecido por la nueva ley ${ }^{13}$. Entonces en la interpretación y aplicación de los artículos de la DC no abrogados se deberá tener presente la legislación de MIDI.

\section{B. los criterios guía}

El contexto mediato de la reforma del proceso de nulidad matrimonial lo encontramos en la Exhortación apostólica Evangelii Gaudium (EG). La Iglesia, que responde en sus orígenes al mandato del Señor ha de ser una Iglesia "en salida" (EG 20-24), que no se limita al "simple administrar" lo que ya tiene (EG 25), que vence la tentación de inmovilismo, que es "casa abierta del Padre" (EG 47), no una "aduana" que controle y e impida el acceso (EG 47-49), que se involucra en una "pastoral en conversión” (EG 25-39), en donde la dimensión pastoral y jurídica se involucren y coordinen, no se contraponen, porque ambas están orientadas a la realización de las finalidades y de la unidad de acción propias de la Iglesia; el servicio a la verdad en la justicia, tiene, en

13 Lo mismo se puede señalar, salvo en los cann.1671-1691, que los demás cánones del CICI/83, continúan vigentes -cánones sobre los juicios en general y sobre el juicio contencioso ordinario-. 
efecto, una connotación profundamente pastoral: la edificación de la comunidad cristiana ${ }^{14}$.

¿Qué elementos ha considerado el Papa al momento de modificar el proceso de declaración de nulidad matrimonial? Por un lado, las dos asambleas sinodales de los obispos, la del año 2014 y la del año 2015, dieron cuenta de una realidad: existe un gran número de fieles que viven en situación irregular, quienes se han alejado de la Iglesia o práctica religiosa al no sentirse atendidos, ni acogidos, ni ayudados en su situación personal. Por otro, se hacía urgente reformar el sistema procesal matrimonial porque el actual sistema no estaba dando la respuesta adecuada a los fieles que recurrían a los tribunales eclesiásticos ${ }^{15}$, considerados estructuras alejadas no solo de los fieles sino, también ajena de la estructura pastoral de la misma iglesia: la lentitud de los procesos irritan y cansan ${ }^{16}$. En este contexto se inserta el MIDI:

"Las leyes que ahora entran en vigor quieren mostrar la cercanía de la Iglesia a las familias heridas, con el deseo que a la multitud de los que viven el drama del fracaso conyugal llegue la obra sanadora de Cristo a través de las estructuras eclesiales con la esperanza de que se descubran nuevos misioneros de la misericordia de Dios para con los otros hermanos, en beneficio de la institución familiar" ${ }^{17}$.

Esta reforma, que coloca la búsqueda de la verdad y la defensa de la indisolubilidad en el centro de la actividad judicial, no es solo una simplificación y agilización del procedimiento a seguir, sino también, lo que es más importante, una revisión de los criterios y actitudes de la

14 FRANCISCO, Discurso a la Rota Romana, de 24 de enero de 2014, AAS 106 [2014] 89-90.

15 La III Asamblea General Extraordinaria del Sínodo de los Obispos, celebrada del 5 al 19 de octubre de 2014, se preguntaba ya en su documento preparatorio, si un proceso canónico más ágil en orden al reconocimiento de la declaración de nulidad del vínculo matrimonial podría ofrecer realmente un aporte positivo a la solución de las problemáticas de las personas implicadas en las situaciones de fracasos matrimoniales, y en caso afirmativo en qué forma. Cf. SÍNODO DE LOS OBISPOS, III Asamblea General Extraordinaria, Los desafíos pastorales sobre la familia en el contexto de la Evangelización, Documento preparatorio, III, 4.f., Ciudad del Vaticano, 2013.

16 FRANCISCO, Restrictus "ex audientia".

17 FRANCISCO, Restrictus "ex audientia”. 
administración de justicia eclesiástica ${ }^{18}$. El Proemio habla incluso de la necesaria "conversión" de los operadores de justicia y de las estructuras eclesiásticas, muchas veces experimentadas lejanas y poco empáticas y poco prolijas en sus competencias matrimonial-jurídicas. En palabras de Francisco a la Signatura Apostólica el año 2013 "el servicio a la justicia como un compromiso de vida apostólica, requiere que se ejerza teniendo la mirada fija en la imagen del Buen Pastor, que se inclina hacia la oveja extraviada y herida" ${ }^{19}$. El Proemio, después de reivindicar que el ejercicio de la potestad judicial es una potestad eclesiástica encomendada por Cristo a Pedro y sus sucesores, presenta en ocho números los principios que guían esta reforma procesal matrimonial, considerada una adecuación de la salus animarum a la realidad de muchos fieles y un reconocimiento y defensa de la propiedad de la indisolubilidad del matrimonio.

La primera parte de MIDI establece los "criterios guías fundamentales de la reforma”, criterios que manifiestan la ratio legis et la mens legislatoris. Con estos criterios la normativa de la nueva ley debería ser correctamente interpretada, comprendida y aplicada. Inspiran estos principios la justicia y la misericordia sobre la verdad del vínculo de quienes han experimentado el fracaso matrimonial. Estos criterios son de hecho la guía más segura para el examen y la interpretación del texto en su conjunto, que quiere "mostrar la cercanía de la Iglesia a las familias heridas" ${ }^{20}$, y que tiene un objetivo eminentemente pastoral: mostrar la solicitud de la Iglesia hacia los fieles que esperan una rápida verificación de su situación matrimonial ${ }^{21}$.

18 La Iglesia, como afirma Francisco en la Exh. Apost. Evangelii Gaudium (EG), ha de involucrarse en una "pastoral en conversión" (nn. 25-39 EG). Esta es la predisposición que se exige en todos los ámbitos de la acción pastoral de la Iglesia, también en este ámbito concreto que es el de la administración de la justicia eclesial, ámbito que -como ha recordado repetidas veces el Papa Francisco- pertenece directa y esencialmente a la acción pastoral de la Iglesia y a su misión evangelizadora, y en cuanto tal, también esta dimensión está necesitada de una "conversión pastoral", de esa "conversión de las estructuras" a la que se refiere el Papa Francisco como idea recurrente: la conversión de las estructuras pastorales ha de tocar necesariamente la actividad judicial.

19 FRANCISCO, Discurso a la plenaria del Supremo Tribunal de la Signatura Apostólica, de 8 de noviembre de 2013, AAS 105 (2013) 1153.

20 FRANCISCO, Rescripto “ex audientia”.

21 FRANCISCO, Discurso a los participantes en un curso organizado por la Rota Romana, 12 marzo 2016. 
Veamos cuáles son y qué significan estos criterios guías, de naturaleza pastoral, jurídica y teológica, que nosotros analizaremos no individualmente sino de manera relacionada e integrada ${ }^{22}$ :

B. 1) No se innova ni en la naturaleza declarativa del proceso judicial de nulidad matrimonial (no es un proceso constitutivo de la nulidad) ni en la doctrina (no se han introducido nuevos capítulos de nulidad):

a. ¿Nuevo tipo de proceso de nulidad matrimonial? El mayor reto al que estamos llamados todos los operadores jurídicos en la Iglesia es buscar la verdad del vínculo conyugal y proteger y defender su indisolubilidad. En diversos medios de comunicación social, subrayando la dimensión pastoral que subyace a la base de esta reforma, se la ha presentado como conteniente un proceso de refundación teológico-canónica de la nulidad del matrimonio. Para algunos, incluso, habría introducido el "divorcio" católico. Veamos qué tan verdadera es esta afirmación.

No hay duda de que el MIDI protege "[...] la verdad del sagrado vínculo conyugal” y su indisolubilidad. Lo indica expresamente en el Proemio: "con el transcurrir de los siglos, la Iglesia, en materia matrimonial, adquiriendo conciencia más clara de las palabras de Cristo, ha comprendido y expuesto más profundamente la doctrina sobre la indisolubilidad del vínculo del matrimonio, ha elaborado el sistema de la nulidad del consentimiento matrimonial y ha disciplinado más adecuadamente el proceso judicial sobre dicha materia, todo ello de acuerdo con la verdad de fe profesada [...] Consciente de ello, establecí que se iniciara la reforma de los procesos de nulidad del matrimonio [...] salvando siempre el principio de la indisolubilidad del vínculo matrimonial”.

El Proemio, considerando el principio de la seguridad jurídica, afirma que las causas de nulidad serán tratadas por vía judicial, y no administrativa, y dentro de la vía judicial se mantiene el proceso ordinario como "el proceso tipo" para este tipo de procedimientos ${ }^{23}$. Efectivamente MIDI reconoce tres

22 En el proemio se establecen las siguientes: I. Una sola sentencia en favor de la nulidad es ejecutiva; II. El juez único, bajo la responsabilidad del Obispo; III. El mismo Obispo es juez; IV. El proceso más breve; V. La apelación a la Sede Metropolitana; VI. La función propia de las Conferencias Episcopales; VII. La apelación a la Sede Apostólica; VIII. Las disposiciones para las Iglesias Orientales.

23 Francisco justifica el motivo de esta elección procesal: "He hecho esto, por tanto, siguiendo las huellas de mis predecesores, que han querido que las causas de nuli- 
procesos de naturaleza judicial para el estudio de la validez de un matrimonio: el ordinario, el más breve y el documental ${ }^{24}$. Cada uno de ellos de naturaleza declarativa de la nulidad, no constitutiva de la misma. Por lo que, tanto en el proceso más breve, que se considera una excepción ${ }^{25}$, como en el documental, o se alcanza la certeza moral necesaria de la nulidad y se resuelve por la nulidad del matrimonio, o en caso contrario, se remite la causa al proceso ordinario (can. 1687). Entonces, si bien se reconoce la existencia de tres tipos de procesos por los cuales se puede estudiar un matrimonio que ha fracasado, se ha optado por un proceso de naturaleza judicial, en vista a proteger la indisolubilidad matrimonial y el derecho de los fieles a un juicio justo y al recto ejercicio y respeto del derecho de defensa. En línea con el magisterio pontificio esta elección, "[...], lo exige la necesidad de tutelar en el máximo grado la verdad del vínculo sagrado: y eso se asegura precisamente con las garantías del orden judicial".

La reforma al proceso canónico de declaración de la nulidad matrimonial, insistimos, deja firme la doctrina de la indisolubilidad del vínculo matrimonial. La iniciativa pontificia no pretende subvertir la inviolabilidad dogmática de la indisolubilidad, piedra angular del vínculo matrimonial, ni afectar las normas sustantivas de la invalidez del consentimiento matrimonial. Solo aspira a que la disciplina eclesiástica

dad del matrimonio fueran tratadas por la vía judicial, y no por la administrativa, no porque lo imponga la naturaleza del asunto, sino porque lo exige la necesidad de tutelar al máximo la verdad del sagrado vínculo: y esto es exactamente asegurado con las garantías del orden judicial”.

24 Francisco responde que "En la reforma de los procesos he cerrado la puerta a la vía administrativa, que era la vía por la cual podía entrar el divorcio. Y se puede decir que aquellos que piensan en el divorcio católico se equivocan porque este último documento ha cerrado la puerta al divorcio que podía entrar por la vía administrativa. Siempre está la vía judicial [...] Este documento, este motu proprio, facilita los procesos en cuanto al tiempo, pero no se trata de un divorcio, porque el matrimonio es indisoluble cuando es sacramento, y esto la Iglesia no lo puede cambiar", en "Conferencia de prensa del Santo Padre durante el vuelo de regreso a Roma del viaje apostólico a Cuba y a los Estados Unidos de América”.

25 En este sentido, véase la respuesta del Pontificio Consejo para los Textos Legislativos (prot. No 15139/2015) del 1 de octubre de 2015, que justifica la necesidad de consentimiento expreso de ambas partes para poder iniciar el proceso más breve: "This explicit consent is foremost necessary because the brief process is an exception to the general norm». http:/www.delegumtextibus.va/content/te- stilegislativi/it/ risposte-particolari/procedure-per-la-dichiarazione-della-nullita-matrimoniale. html (consultado 4-5-2016) 
sea eficientemente aplicada, esté cerca de los fieles que han visto fracasado su proyecto matrimonial y sea más coherente con la verdad de la fe que se profesa: cuando el matrimonio es un verdadero matrimonio, es indisoluble; pero cuando esa realidad no es un matrimonio no hay nada indisoluble. El matrimonio es indisoluble cuando es sacramento, y esto la Iglesia no lo puede cambiar ${ }^{26}$. El procedimiento judicial que se realiza en cada uno de los tres procesos contenientes en MIDI, justamente es una opción procesal por la cual el Papa quiere garantizar la defensa de esta verdad de fe, con lo que cierra definitivamente la puerta a la entrada hipotética del divorcio en la Iglesia y al laxismo al momento de fallar estos procesos judiciales de nulidad matrimonial ${ }^{27}$.

Respondiendo a nuestra anterior pregunta, nadie puede dudar que en el terreno de los principios, la búsqueda de la verdad y la protección de la indisolubilidad estén en la intentio y en la ratio del MIDI. Otra cuestión es si el modo como se han regulado determinadas instituciones procesales en este documentos es el más idóneo para la consecución de esa finalidad.

b. ¿Nuevas causales de nulidad matrimonial? Las "circunstancias" señaladas en el art. $14 \$ 1$, que pueden permitir tratar la causa de nulidad del matrimonio a través del proceso más breve según los cánones 1683-1687, han sido consideradas por muchos nuevas causales de nulidad y con igual valor jurídico. Nos preguntamos, ¿̇ienen todas estas circunstancias el mismo valor jurídico o naturaleza procesal? Para nosotros no. Lo explico.

El art.14, en línea con la hermenéutica de continuidad y a la luz del can. $6 \$ 2$, señala a modo ejemplificativo, circunstancias que pueden permitir tratar la causa de nulidad del matrimonio a través del proceso brevior, pero no señala circunstancias que por sí solas son invalidantes del matrimonio en cuestión. Sostenemos que las mismas no indican nuevas causales de nulidad. Son situaciones, hechos y condiciones, que

26 F. Coccopalmeiro afirma al respecto que "Se trata -dijo- de un proceso que conduce a la declaración de nulidad que lleva, en otros términos, a apurar, en primer lugar, si un matrimonio es nulo y después, en caso positivo, a declarar la nulidad. No se trata, por lo tanto, de un proceso que conduzca a la anulación del matrimonio. Nulidad es distinto de anulación y declarar la nulidad de un matrimonio es absolutamente diverso de decretar la anulación del matrimonio", en "Discurso durante la Presentación de la Nueva Ley".

27 FRANCISCO, "Conferencia de prensa del Santo Padre durante el vuelo de regreso a Roma del viaje apostólico a Cuba y a los Estados Unidos de América”. 
si bien pueden ser relevantes para probar lo alegado en el libelo, no son circunstancias constitutivas en sí mismas de plena prueba o certeza moral suficiente para declarar la nulidad matrimonial. Son "argumentos particularmente evidentes", son elementos sintomáticos de invalidez del consentimiento matrimonial que sostienen la petición de nulidad, según la jurisprudencia de la Rota Romana y poseen naturaleza heterogénea según sea la circunstancia de que se trate que pueden ser fácilmente comprobadas. No causales de nulidad matrimonial

Para interpretar correctamente el art.14, que señala estos elementos indicativos, en línea con la tradición jurídica, se deben distinguir:

a) Las circunstancias ya reconocidas, asumidas y aceptadas por la jurisprudencia de la Rota Romana y la práctica de los Tribunales, como causas de nulidad matrimonial (matrimonio celebrado por causa extraña al matrimonio, violencia física, falta de uso de razón comprobada, obstinada permanencia en relación extraconyugal (simulación parcial), ocultamiento doloso de la esterilidad (can.1098: error doloso), ocultamiento doloso grave enfermedad, hijos precedentes relaciones, encarcelaciones (error doloso));

b) De las meras circunstancias que pueden ayudar en la admisión de la causa al proceso brevior, pero que por sí solas no pueden ser suficientes para declarar la nulidad matrimonial porque no tienen por sí solas un valor jurídico preciso pro nullitatis (embarazo, falta de fe, brevedad de la convivencia matrimonial, aborto procurado para impedir la procreación).

Entonces, si estamos a la mente del legislador podemos sin duda afirmar que la reforma procesal en cuestión se coloca dentro de la disciplina eclesiástica y de la reglamentación dogmática del matrimonio y no pretende abordar ni la indisolubilidad del matrimonio ni modificar ni establecer un nuevo régimen de invalidez del consentimiento matrimonial ni nuevas causales de nulidad.

B. 2) Responsabilidad teológica y protagonismo judicial del Obispo diocesano (cfr. Can. $1673 \$ 1$ e DC art.22).

La reforma del proceso matrimonial pone al centro de la preocupación de los Obispos la preocupación por los fieles que han fracasado en su matrimonio y que están necesitados de un especial cuidado pastoral. Al centro de esta reforma procesal se ha recordado el rol fundamental 
que le corresponde al Obispo, como pastor propio, padre y juez, en la administración de justicia en su diócesis, dimensión ineludible de su función ordinaria de gobierno ${ }^{28}$. Responsabilidad que va mucho más allá del ejercicio inmediato y personal de la función judicial. Lo anterior aparece claramente en la afirmación del n. III del Proemio: "se ha establecido hacer evidente que el mismo obispo en su Iglesia, de la que es constituido pastor y cabeza, es por eso mismo juez entre los fieles que se le han confiado [...] no deje la función judicial en materia matrimonial completamente delegada a los oficios de la curia”.

Nos preguntamos en nuestra reflexión ¿Quién es el Obispo diocesano, juez de sus fieles? El código afirma que el Obispo diocesano en la Iglesia particular encomendada a su cuidado es el pastor propio y solícito de su grey (cann. 369; 383; 386; 391-393). Por su parte, afirma LG27, en el ejercicio de su potestad propia, tenga siempre ante los ojos, el ejemplo del Buen Pastor. Entonces, como pastor propio, le corresponde especialmente guiar hacia la unidad a esa determinada porción del pueblo de Dios. Y, como pastor solícito, debe acompañar y estar atento a "todos los fieles que se le confían, cualquiera que sea su edad, condición o nacionalidad, tanto si habitan en el territorio como si se encuentran en él temporalmente, manifestando su afán apostólico también a aquellos que, por sus circunstancias, no pueden obtener suficientemente los frutos de la cura pastoral ordinaria, así como a quienes se hayan apartado de la práctica de la religión” (can. $383 \$ 3$ ) ${ }^{29}$. En virtud de tal servicio de unidad y caridad, custodio de la unidad en la fe y en la disciplina, ha sido constituido en una determinada Iglesia particular, juez propio $(\text { can. 375) })^{30}$.

28 Se afirma en la Relación final del Sínodo Ordinario de Obispos, n.82, documento posterior a la publicación del texto de MIDI, "La actuación de este MP constituye una gran responsabilidad para los Obispos diocesanos, que han sido llamados a juzgar ellos mismos algunas causas de nulidad matrimonial, y de todos modos, a asegurar un acceso más fácil de los fieles a la justicia".

29 P. PINTO, "Esperanza sin miedos", Entrevista al decano de la Rota sobre el nuevo proceso matrimonial, en http://www.osservatoreromano.va/es/news/esperanza-sinmiedos\#sthash.g53tiH4m.dpuf (consultado 14-05-2016)

30 En la consagración episcopal el Obispo ha recibido una serie de funciones con las cuales realiza el servicio y por las cuales manifiesta toda su autoridad. En el juicio de idoneidad de los candidatos al episcopado, se requiere confirmar la presencia de cualidades y virtudes humanas y divinas, entre las cuales destacamos el celo por las almas. Cf. can. 378, 1 . Cf. O. Semmelroth, "La Chiesa, nuovo popolo di Dio", 
Como se puede ver la descripción que hace la legislación de la Iglesia acerca del ministerio episcopal no es en ningún caso ni estática ni autoritaria, sino principalmente relacional, viva, atenta y activa. No solo reconoce su potestad de gobierno, sino que, además, la fundamenta en su finalidad: "debe mostrarse solícito con todos los fieles que se le confían" (can. 383) y "enseñar y explicar a los fieles las verdades de fe que han de creerse y vivirse" (can. $386 \$ 1$ ) 31 . Como afirma LG27 "En virtud de esta potestad, los Obispos tienen el sagrado derecho y ante Dios el deber de legislar sobre sus súbditos, de juzgarlos [...]”. Justamente en este horizonte ministerial que al Obispo diocesano en relación a su Iglesia particular, le corresponde una potestad ordinaria, propia e inmediata, necesaria para el ejercicio de su función judicial (cann. 381, $\$ 1$; 369; 375-376): él es el primer responsable de juzgar y resolver los casos que se presenten al Tribunal y en el ejercicio de esta función judicial episcopal está destinado no solo a la resolución del caso sino también a ser instrumento para que los fieles encomendados a su cuidado alcancen los frutos de salvación. Es decir, no solo por su potestad jurisdiccional al frente de su Iglesia particular, sino también por su responsabilidad teológica y su finalidad salvífica el Obispo diocesano es juez en su diócesis y moderador de toda la administración de justicia en ella, "tarea de grave responsabilidad” (can. 376) ${ }^{32}$. Deberá, por lo mismo, promover, indicar, convocar, moderar con todas sus fuerzas y a todas las fuerzas de la Iglesia particular para que de todas ellas se realice el bien de la justicia y de la verdad en la realidad matrimonial que ha fracasado ${ }^{33}$.

en G. BARAUNA, ed., La Chiesa del Vaticano II, studi e commenti intorno alla Costituzione dommatica "Lumen Gentium", Firenze 1965, 445-447.

31 El ejercicio de su ministerio, en bien de la Iglesia (can. 1752), se debe realizar de acuerdo al principio de la unidad de la fe y del gobierno (can. $386 \$ 2$ ), de la distribución y de tareas y funciones (can. 394), de la complementariedad y colaboración (can. 375).

32 Cf. e. CAPPEllini, «Comunione ecclesiale e Codex Iuris Canonici», QDPE 2 (1985), 121.

33 Establece el Directorio para el Ministerio Pastoral de los Obispos Apostolorum successores n 68 que, además de observar y hacer observar las normas de procedimiento establecidas para el ejercicio de la potestad judicial: “d) el Obispo, consciente del hecho que el tribunal de la diócesis ejercita su misma potestad judicial, vigilará a fin de que la acción de su tribunal se desarrolle según los principios de la administración de la justicia en la Iglesia. En particular, teniendo en cuenta la singular importancia y relevancia pastoral de las sentencias que se refieren a la validez o nulidad del matrimonio, dedicará una especial atención a tal sector, en sintonía con las in- 
Dos son las principales afirmaciones que en este sentido aparecen en MIDI:

a) En el primer párrafo del Proemio, inspirado en el CVII, el Papa Francisco establece:

"El Señor Jesús, Juez clemente, Pastor de nuestras almas, confió al Apóstol Pedro y a sus Sucesores el poder de las llaves para cumplir en la Iglesia la obra de la justicia y la verdad; esta suprema y universal potestad de atar y desatar aquí en la tierra afirma, corrobora y reivindica la de los Pastores de las Iglesias particulares, en fuerza de la cual éstos tienen el sagrado derecho y el deber delante del Señor de juzgar a sus propios súbditos" ( $L G 27$ ).

b) En el criterio fundamental III:

"El Obispo mismo es Juez: En orden a que sea finalmente traducida en práctica la enseñanza del Concilio Vaticano II en un ámbito de gran importancia se ha establecido hacer evidente que el mismo Obispo en su Iglesia, de la que es constituido pastor y cabeza, es por eso mismo juez entre los fieles que le han sido confiado. Se espera por tanto que, tanto en las grandes como en las pequeñas diócesis, el Obispo mismo ofrezca un signo de la conversión de las estructuras eclesiásticas, y no deje la función judicial en materia matrimonial completamente delegada a los oficios de la curia”.

No se trata de recargar al Obispo con el peso y la tarea de juzgar personalmente las causas de los fieles de su diócesis, porque también puede ejercer esta potestad por medio del Vicario judicial y de los jueces, conforme a la norma del derecho (can. $391 \$ 2$ ), sino la de reconocerle la responsabilidad que le corresponde de salvaguardar la institución del matrimonio y la de procurar con todas sus fuerzas promover la santidad de los fieles (can. 387) poniendo de manifiesto que la función de juzgar

dicaciones de la Santa Sede, y ante la ocurrencia de eventuales abusos, tomará todas las medidas necesarias para que éstos cesen, especialmente aquellos que impliquen el intento de introducir una mentalidad divorcista en la Iglesia", Congregación para los Obispos, en http://www.vatican.va/roman_curia/congregations/cbishops/ documents/rc_con_cbishops_doc_20040222_apostolorum-successores_sp.html (consultado 20-06-2016) 
le es tan propia como la de santificar y enseñar, y que requiere la misma dedicación y preocupación que aquellas.

¿Por qué el Papa ha recordado esta responsabilidad personal de los Obispos diocesanos? Lo que hace MIDI es reconocer que el Obispo diocesano es por derecho divino el juez propio en su diócesis y que comparte con el Papa el deber de tutelar la unidad en la fe y en la disciplina matrimonial ${ }^{34}$. El principio rector del ejercicio de esta como de todas sus potestades está constituido por la «cura animarum» de los fieles encomendados a su cuidado: principio que establece que la principal finalidad del gobierno del Obispo en la diócesis, es el bien espiritual, moral y religioso de los fieles encomendados a su cuidado. Señala el III criterio fundamental del MIDI que en orden a que sea finalmente traducida en práctica la enseñanza del Concilio Vaticano II es necesario hacer evidente que en el vértice de la administración de justicia en la diócesis está el Obispo diocesano, porque ha sido el mismo Jesús quien ha confiado a los Obispos el poder de las llaves para cumplir en la Iglesia la obra de la justicia y la verdad. En esta línea argumentativa afirma LG 27 que "Los Obispos rigen como vicarios y legados de Cristo las Iglesias particulares que se les han encomendado, con sus consejos, con sus exhortaciones, con sus ejemplos, pero también con su autoridad y con su potestad sagrada que ejercitan únicamente para edificar su grey en la verdad y la santidad". Se destaca con este texto la relación directa que existe entre el ministerio episcopal y la cura de almas como finalidad última del gobierno episcopal, y entre esta última y el derecho y la grave responsabilidad que le corresponde al Obispo diocesano de juzgar a sus propios súbditos y de regular todo cuanto pertenece a la administración de justicia en su diócesis, no solo a través de los vicarios o jueces, sino en primera persona. Una explicitación de esta responsabilidad propia la encontramos en lo que afirma Juan Pablo II en el Directorio Apos-

34 "È a tutti nota l'inversione d'impostazione che il Codice di diritto canonico vigente sulla scia del concilio vaticano II, ha introdotto rispetto al codice piano-beneditino in merito alla potestà di cui gode il vescovo diocesano nella sua chiesa particolare. Nel codice precedente il vescovo diocesano era sì considerato come posto a capo ex divina institutione a una Chiesa particolare e perciò con potestà ordinaria (can. 329 \$1). Nello stesso tempo però si rifuggiva dal determinare criteri in base ai quali individuare il contenuto specifico di tale potestà, fino a poter affermare che tale governo era costituito dai poteri affidatagli o riconosciutigli dal diritto": G. P. MONTINI "Alcune riflessioni", 23-24. Ver también G. GHIRLANDA, "Doveri e diritti dei fedeli nella comunione ecclesiale “, La Civiltà Cattolica, 1 (1985), 26. 
tolorum successores cuando establece que "los obispos están llamados a comprometerse personalmente tanto para garantizar la idoneidad de los miembros de los tribunales de los cuales son moderadores, como para verificar la conformidad de las sentencias eclesiásticas con la recta doctrina. Tarea de grave responsabilidad que exige en el Obispo diocesano, ante todo, un profundo sentido de justicia, pero también una adecuada pericia canónica, una experiencia acorde en materia y un particular y permanente cuidado de sus fieles. El Obispo, "constituido pastor y cabeza, es por eso mismo juez entre los fieles que se le han confiado" debe ofrecer un claro signo de conversión personal e institucional, porque, en cuanto pastor de su Iglesia particular, tiene el sagrado "derecho y el deber delante del Señor, de juzgar a sus propios súbditos”. A él, juez para sus fieles, le corresponde cumplir la obra de justicia y de verdad en su diócesis, teniendo como ejemplo, a Jesús, "Juez clemente y Pastor de nuestras almas”, y como fin, el bien de los fieles que se le han confiado a quienes debe manifestar su cercanía judicial.

En esta responsabilidad el Obispo no puede pensar que el proceder de sus tribunales es una cuestión meramente "técnica", de la que pueden desinteresarse, encomendándola enteramente a sus jueces o vicarios (cann. 391, 1419, 1423,1) 35. "Completamente", como señala el criterio III, no significa una prohibición absoluta de encomendar a otros su ejercicio, porque precisa el mismo criterio que puede ocurrir que en algunas circunstancias puede recurrir a la colaboración y al trabajo de los vicarios judiciales y jueces. El can. $1419 \$ 1$ afirma que: "En cada diócesis, y para todas las causas no exceptuadas expresamente por el derecho, el juez de primera instancia es el Obispo diocesano, que puede ejercer la potestad judicial por sí mismo o por medio de otros de acuerdo con los cánones que siguen”. Entonces, sea personalmente, sea por medio de otros, MIDI establece una mayor implicancia del Obispo diocesano en la justicia eclesiástica y en los procedimientos de nulidad matrimonial, como una de las tareas y responsabilidades importantes que tiene con el Pueblo de Dios.

5 JUAN PABLO II Discurso al Tribunal de la Rota Romana con ocasión de la apertura del año judicial, 29 de enero de 2005, n.4, en http://w2.vatican.va/content/johnpaul-ii/es/speeches/2005/january/documents/hf_jp-ii_spe_20050129_roman-rota.html (consultada el 20-08-2016). 
Teniendo en cuenta esta potestad principal y ordinaria del Obispo en el ejercicio de la potestad judicial en su diócesis, a partir de las distintas prerrogativas, derechos y obligaciones de las cuales el Obispo es titular, emerge del documento MIDI una detallada descripción de la figura del Obispo juez, padre y pastor bueno. En la práctica, este compromiso del obispo en el desempeño de la función judicial habrá de traducirse en diversas actuaciones concretas, muchas de ellas reconocidas explícitamente en la legislación universal, pero también otras muchas en esta reforma por medio de la legislación particular. A título meramente indicativo me permito referir las siguientes:

Es responsabilidad del Obispo diocesano organizar del mejor modo este servicio de la pastoral familiar con una mínima pero suficiente estructura y junto a los párrocos deberá acompañar con preocupación a los esposos separados o divorciados, especialmente a aquellos que eventualmente han abandonado la práctica religiosa (art. 1; cann. 383,1 y 529,1). Como Padre y Pastor de esa determinada porción de la Iglesia, debe prestar particular solicitud a estas personas. Hacia ellos, le recuerda la exhortación Familiaris consortio, deberá dedicar interés, atención, tiempo, personas, recursos y, sobre todo, apoyo personal a las familias y a cuantos, en las diversas estructuras diocesanas, le ayudan en la pastoral de la familia ${ }^{36}$.

El art. $8 \$ 1$ de las Reglas Procesales en línea con el can. $1673 \$ 2$ obliga al Obispo a constituir para su diócesis un tribunal, respecto del cual está llamado a ejercer funciones de moderador, como expresión del derecho del fiel a la tutela judicial efectiva (can. 221), y al ejercicio del ius connubii (can. 1058) en términos de verdad y justicia, en definitiva, por las exigencias de la salus animarum (can. 1752)

Libertad del Obispo a la hora de constituir su tribunal. El Papa pretende con esta Reforma, agilizar lo más posible no solo la tramitación de las "nulidades manifiestas", con el proceso más breve ante el Obispo, sino también el proceso ordinario. Como concreción de esta libertad se establece que si no es posible constituir el tribunal colegial sea en el tribunal diocesano sea en el tribunal eclesiástico cercano que ha sido elegido conforme al can. $1673 \$ 2$, el Obispo puede confiar la causa a un juez único,

36 JUAN PABLO II Exhortación apostólica Familiaris consortio, n.73, en http:// w2.vatican.va/content/john-paul-ii/es/apost_exhortations/documents/hf_jp-ii_ exh_19811122_familiaris-consortio.html (consultada el 30-9-2016). 
clérigo, (can.1673\$4), sin necesidad ahora de solicitar la prórroga de competencia a la Signatura Apostólica, ni el permiso de la Conferencia Episcopal y sin que sea necesario aplicar los requisitos exigidos en el can.1425 \$4 al juez único. En caso que si se pueda constituir un tribunal colegial para la diócesis, estos mismos pueden estar constituidos por dos jueces laicos (mujeres y/o varones) presididos por un clérigo (can.1673 $\$ 3)$, sin las limitaciones establecidas en el can.1421 \$2.

El can.1673 \$1, va a explicitar la función de juez de primera instancia del obispo diocesano en los procesos matrimoniales y va a señalar, además, que en el caso de procesos de nulidad matrimonial, él es el juez ordinario por ser estas causas matrimoniales, causas especiales, cuando prevé que: "En cada diócesis el juez de primera instancia para las causas de nulidad del matrimonio, para las cuales el derecho no haga expresamente excepción, es el Obispo diocesano, que puede ejercer la potestad judicial por sí mismo o por medio de otros, conforme al derecho”. La DC, por su lado, en su art. 22 establece, en relación con el Obispo diocesano: " $\$ 1$. En cada diócesis, para las causas de nulidad de matrimonio no exceptuadas expresamente por el derecho, el juez de primera instancia es el Obispo diocesano, que puede ejercer la potestad judicial por sí mismo o por medio de otros, de acuerdo con el derecho (cf. c. 1419 \$1). Pero la DC agrega, en el " $\$ 2$. Sin embargo, conviene que no juzgue por sí mismo a no ser que lo exijan causas especiales”. Entonces, de acuerdo a ambas normas, siempre se ejercita la potestad judicial episcopal, sea que la ejercite personalmente él sea que lo haga por medio de otros. Lo que ocurre es que la nueva ley expresa que estos procesos son especiales por la sacramentalidad de su objeto.

El proceso más breve, creado ex novo, viene regulado de modo sumamente sintético en el art. 5 del MIDI, que da una nueva redacción a los cann. 1683-1687 (ulteriores precisiones y aclaraciones en los arts. 14-20 de las $\mathrm{RP})$. El proceso más breve no es un proceso administrativo es siempre un proceso de naturaleza judicial. El mismo Papa, como lo hemos ya mencionado, ha excluido este tipo de procedimiento administrativo, para el estudio de la nulidad de un matrimonio. El más breve es un proceso que se concluye siempre con una sentencia judicial y con la posibilidad de una apelación (can. 1679). Estas causas especiales, a la luz del can. 1683 y del principio de reforma IV, ocurre con mayor claridad en el proceso más breve: le corresponde exclusiva y privativamente a él juzgar esas causas (can. 1683). ¿Por qué en el proceso más breve el juez es el Obispo? 
El Proemio afirma que como "el buen pastor", está obligado a ir al encuentro de los fieles que tienen necesidad de especial cuidado y que esto lo realiza particularmente cuando se hace cargo en primera persona de la resolución de los procesos más breves, establecidos para resolver los casos de nulidad más evidente. Francisco precisa que "No se me escapa, sin embargo, cuánto un juicio abreviado pueda poner en riesgo el principio de la indisolubilidad del matrimonio; precisamente por esto he querido que en tal proceso sea constituido juez el mismo Obispo, que en virtud de su oficio pastoral es con Pedro el mayor garante de la unidad católica en la fe y la disciplina”. Es este el motivo, teológico y disciplinar, que fundamenta esta exclusividad episcopal en este tipo de proceso: como padre, comprometido a vivir como el buen Pastor, le corresponde promover eficazmente el bien de la Iglesia, defender la unidad de la fe y la disciplina común y ser, para ella, en cuanto responsables inmediato de la misma, el principio y fundamento visible de comunión ${ }^{37}$.

Preocupado por el bien de los suyos, debe presidir y conducir personalmente en su Iglesia el proceso judicial matrimonial. En cumplimiento de esta actividad judicial el Obispo, pastor propio, deberá proveer personalmente a todo lo que sea necesario para el fiel cumplimiento de este ministerio, organizando completamente la actividad y, además, seleccionado, formando y acompañando a los operadores de justicia que son también pastores ${ }^{38}$. Es el primer garante de este ministerio eclesiástico a través del ejercicio de sus funciones de vigilancia, reglamentación y control estricto de la misma. En términos generales esta responsabilidad judicial de su ministerio episcopal se debería traducir en las siguientes actuaciones: 1. Estableciendo las directrices generales de actuación de todos los operadores jurídicos de su tribunal, especialmente de los miembros del mismo; 2. Buscando personas idóneas para el ejercicio de la función judicial, con formación y dedicación "exclusiva" o "prioritaria"; 3. Estableciendo mecanismos efectivos de control de su activi-

37 "Esa dimensión pastoral de vuestro ministerio - que es la primera y esencial del mismo- os hace los hombres de la comunión, los padres y hermanos de la comunidad de creyentes que os ha sido confiada; os hace los especialistas en el "sensus Ecclesiae", o sea de la Iglesia, universal y local, que en la historia prosigue la misión de Cristo Redentor entre los hombres. Ese sentido pastoral es el que habrá de guiar siempre vuestra fidelidad a Dios y la lealtad a los hombres vuestros hermanos.»: Juan Pablo II, Discurso a los Obispos de Chile en visita ad limina, 19.10.1984, 3. FRANCISCO, Discurso a la Rota, 24 de enero 2014. 
dad, de modo que esta responda a criterios de celeridad y diligencia; 4 . Prestando atención al tenor de los pronunciamientos de su tribunal, de modo que se proteja y garantice el favor veritatis y el favor matrimonii y el principio de indisolubilidad; 5. Procurando que los fieles que lo requieran "tengan asegurada la gratuidad de los procedimientos" (Proemio y art. $7 \$ 2) ; 6$. Estableciendo mecanismos correctores de la negligencia, la impericia o el abuso a la hora de administrar justicia ${ }^{39}$.

B.- 3) La preocupación por procesos diligentes, ágiles, simples y accesibles. Uno de los grandes retos de la reforma es contribuir a que, de manera efectiva, la tramitación de los procesos de nulidad responda a criterios de diligencia y celeridad ${ }^{40}$. Dos son los principios que orientan hoy en día la administración de justicia matrimonial: la pastoralidad ${ }^{41} \mathrm{y}$ la caridad como signos de misericordia, las cuales deben hacer efectiva la verdadera "conversión de las estructuras" (EG 27). La intención del legislador ha sido justamente corregir los desajustes judiciales existentes en la Iglesia y configurar un procedimiento que, protegiendo la indisolubilidad y la verdad del vínculo conyugal, responda también a los criterios de celeridad-diligencia y simplicidad. Sin duda alguna, uno de los grandes retos de la reforma es contribuir a que, de manera efectiva, la tramitación de los procesos de nulidad responda a estos criterios. En total sintonía con las propuestas Sinodales, afirma Francisco en la presentación de MIDI que, "he decidido establecer con este Motu proprio disposiciones con las cuales se favorezca no la nulidad de los matrimonios, sino la celeridad de los procesos, favoreciendo el desarrollo ágil de los procesos judiciales y, no en menor medida, una adecuada simplificación, asegurando el acceso a la justica eclesiástica de modo más fácil”.

39 CARLOS M. MORÁN BUSTOS "Retos de la reforma procesal de la nulidad del matrimonio", en http://blogs.comillas.edu/canonico/2016/5/19/retos-de-la-reforma-procesal-de-la-nulidad-del-matrimonio/ (consultado 15-6-2016)

40 "Durante el reciente itinerario sinodal sobre la familia, habían surgido fuertes expectativas para hacer más ágiles y eficaces los procedimientos para la declaración de nulidad matrimonial”, en FRANCISCO, Discurso a los participantes en un curso organizado por el Tribunal de la Rota Romana.

41 Signo de pastoralidad y considerando el principio de la libre valoración de las pruebas (cfr. 1608,2; DC 247,4) por el cual el juez debe valorar según conciencia las pruebas (can. 1608,3, DC art. 180, 202) por las que buscará alcanzar la necesaria certeza moral, el nuevo can. $1678 \$ 1$, se refiere al mayor valor que se da a las confesiones y declaraciones de las partes, especialmente cuando expresan las intenciones con las que se decidió y celebró el matrimonio. 
Reafirmamos que, la intención del legislador no ha sido favorecer ni facilitar la nulidad matrimonial: agilidad y rapidez, no significa ni debe significar facilitación ni descuido procesal ${ }^{42}$.

La celeridad del proceso es una exigencia moral de la justicia. La brevedad del proceso no debe ir en detrimento de la búsqueda seria de la verdad, no debe poner en duda la certeza del derecho, no debe perjudicar los derechos de las partes procesales. Haciéndose cargo de una propuesta del Sínodo de los Obispos ${ }^{43}$, el Papa establece, de hecho, procesos judiciales más rápidos y accesibles. Con esta finalidad se contienen disposiciones con las cuales se favorece ciertamente, no la facilitación en la declaración de nulidad matrimonial, sino la celeridad de los procesos y la adecuada simplificación procesal, de modo que se evite que, a causa de un retraso injustificado e injusto en la definición del dubio planteado en sede judicial, el corazón de los fieles que esperan la clarificación del propio estado no quede largamente oprimido por las tinieblas de la duda. Una justicia demorada es una justicia denegada, como se concluye de la lectura de los cann. 212-213 y 221. Quedará a la práctica misma y a la doctrina profundizar el ejercicio de estos cánones para que se asegure siempre la calidad y la profesionalidad en el estudio jurídico del matrimonio acusado de nulidad. La agilidad procesal, insistiendo en la naturaleza declarativa de los procesos de nulidad y en la necesidad de certeza moral en los términos del art. 12 de la Ratio Procedendi que todos conocemos, no debe significar desidia o irresponsabilidad en el desarrollo del proceso de nulidad matrimonial.

Agilizar y dar celeridad encuentran en MIDI traducción en diversas disposiciones concretas con las que se integran en la pastoral familiar

42 "Maggiore celerità, non faciloneria": O. DE BERTOLIs Papa Francesco riforma il processo matrimoniale canonico, en La Civiltá Cattolica, CLXVI/IV (2015) 68.

43 La Relación del III Sínodo Extraordinario de Obispo del año 2014, afirmaba al respecto, "la necesidad de hacer más accesibles y ágiles [...] los procedimientos para el reconocimiento de los casos de nulidad", SÍNODO DE LOS OBISPOS, III Asamblea general extraordinaria, "Los desafíos pastorales de la familia en el contexto de la evangelización, Relatio synodi, 48. 
varias instituciones procesales ${ }^{44}$. A título meramente indicativo me permito referir las siguientes ${ }^{45}$ :

La creación de una fase previa de investigación "prejudicial o pastoral", la cual puede resultar ciertamente una ayuda para las partes y al tribunal porque se encontraría con un expediente judicial mejor preparado (art.2).

La modificación de los títulos de competencia en los términos del can. $1672,2^{\circ}$, en concreto, sobre la base del «domicilio o cuasidomicilio de una o ambas partes» (arts. $7 \$ \$ 1-2$ y $8 \$ \$ 1-2$. En efecto, para establecer hoy la competencia de cualquier Tribunal eclesiástico a los fines de tramitar un proceso matrimonial de nulidad, bastará con adquirir un cuasidomicilio dentro del término de la demarcación del Tribunal del que se trate (can. $102 \$ 2$ ).

La participación de los laicos como jueces: la norma del can.1673 $\$ 3$ supera las limitaciones del can. $1421 \$ 2$, de modo que ya no se requiere para proceder a nombrar a un juez laico ni que se verifique una situación de necesidad, ni tampoco el permiso de la Conferencia Episcopal.

La posibilidad de un tribunal constituido por un juez único (can. 1673 $\$ 4$ ). Si no es posible constituir un tribunal colegial (can. $1673 \$ 3$ ), se permite que el obispo pueda encomendar la causa a un juez único, que ha de ser clérigo, para lo cual no es necesario el permiso de la conferencia episcopal (can. $1425 \$ 4$ ).

44 Los Tribunales eclesiásticos, por su misma naturaleza pastoral, no son una curia extraña y aparte, sino la misma y parte de la articulación general de la pastoral familiar de la iglesia diocesana.

45 Morán, a quien sigo en este tema, señala que estas novedades se pueden encontrar en: $1^{\circ}$.- La creación de una fase previa de investigación «prejudicial o pastoral»; $2^{\circ}$.- La modificación de los títulos de competencia en los términos del can. 1672, $2^{\circ}$, en concreto, sobre la base del «domicilio o cuasidomicilio de una o ambas partes»; $3^{\circ}$.- La participación de los laicos como jueces, y la posibilidad del juez monocrático (aunque se mantiene la colegialidad como criterio general); $4^{\circ}$.- La necesidad de constituir el tribunal en la diócesis (can. 1673 \$2), y en caso de no existir, la obligación del obispo de procurar la formación de personas que puedan desempeñar este servicio en el tribunal que habría de constituirse (art. 8 \$1), y la posibilidad también de acceder a otro tribunal diocesano o interdiocesano cercano; $5^{\circ}$.- La posibilidad de activar el proceso breve ante el obispo si se verifican los requisitos del can. $1683 ; 6^{\circ}$.- La ejecutabilidad de un única sentencia declarativa de la nulidad del matrimonio (can. 1679), en C. MORÁN "Retos de la reforma". 
La necesidad de constituir el tribunal en la diócesis (can. 1673\$2), y en caso de no existir, la obligación del obispo de procurar la formación de personas que puedan desempeñar este servicio en el tribunal que habría de constituirse (art. $8 \$ 1$ ), y la posibilidad también de acceder a otro tribunal diocesano o interdiocesano cercano, todo ello sin necesidad de ulteriores autorizaciones por parte de la Signatura Apostólica.

El proceso breve ante el obispo, proceso que ciertamente se desarrollará de modo más ágil y con un desarrollo temporal más breve: en efecto, si se verifican los requisitos del can. 1683 .

Una sola sentencia en favor de la nulidad es ejecutiva. La mayor novedad que ha introducido la reforma del proceso de nulidad matrimonial es la abolición de la doble sentencia conforme ${ }^{46}$. Afirma el Papa en el primer criterio guía, que ha parecido oportuno no exigir más "una doble decisión conforme a favor de la nulidad del matrimonio, para que las partes sean admitidas a nuevo matrimonio canónico, sino que sea suficiente la certeza moral alcanzada por el primer juez, a norma del derecho”. Es decir, se ha abrogado la obligación de la doble sentencia conforme a favor de la nulidad del matrimonio para poder celebrar otro nuevo, dando fuerza ejecutiva a la sentencia de primer grado (can.1679).

Recurso de apelación. La apelación en la reforma ha adquirido la naturaleza de contrapeso a la abolición de la exigencia de la doble sentencia conforme. Este recurso no es un deber impuesto por la ley, como se establecía en el ex can. 1682, sino un derecho sancionado en la parte legislativa del MIDI, de quien se considere perjudicado por la sentencia declarativa de nulidad, cann. 1679-1680. Acerca del mismo debemos clarificar, para no generar confusiones innecesarias en relación a lo establecido en el MIDI. Afirma el nuevo can.1679, que "la sentencia que por primera vez ha declarado la nulidad del matrimonio (cualquiera sea la instancia), cumplidos los términos establecidos en los cánones 16301633 (para presentar el recurso de apelación) se hace ejecutiva”. No es exacto afirmar, como algunos han pretendido, que se haya abolido o prohibido de modo absoluto la posibilidad de apelar o la necesidad de la "doble sentencia conforme", sino que hay una nueva regulación del mismo en el pleno reconocimiento del derecho procesal de defensa. Hay

46 Obligación que fue introducida por Benedicto XIV con la Constitución Dei Miseratione del 3 noviembre 1742, en Bullarium, I, Romae 1746, 83. 
una serie de nuevos cánones y toda la remisión que hace la MIDI a los cánones aún vigentes del $\mathrm{CIC} / 83$, que regulan la presentación, la prosecución, los requisitos y exigencias de admisibilidad, el tratamiento del recurso de apelación (cann. 1680-1682 e 1687; 1630-1635).

Lo que sí ha sido abrogado por MIDI de modo claro es la "obligación" o la "necesidad", ipso iure o ex oficio, de la apelación al tribunal de segunda instancia. La sentencia pro nulitatis no recurrida dentro del plazo establecido en el can. 1630-1633, se hace ejecutiva (can. 1679), lo que no quiere decir que se prohíbe toda posibilidad de apelación de la sentencia cuanto se estime justo hacerlo, sea esta afirmativa o negativa de la nulidad, si alguna de las partes se considera perjudicada por la misma sentencia (can. $1680 \$ 1$ ). No presentar la apelación dentro del plazo perentorio legal, equivale a renunciar al derecho que al titular del mismo la ley le otorga. Repetimos, permanece íntegro el derecho a apelar de los cónyuges y del promotor de justicia y del defensor del vínculo (can. 1680). Incluso se reafirma en el criterio de reforma VII la posibilidad de la apelación al Tribunal ordinario de la Sede Apostólica, es decir a la Rota Romana (cann. 1680-1681). Hay una cuestión que deseo destacar. De acuerdo a la estructura del art. 4 y del texto del can. 1679, que reconoce el derecho de apelación, en razón del principio de celeridad del proceso, MIDI regula solamente la apelación en contra una sentencia afirmativa de la nulidad (cann. 1681-1682), dejando la apelación de una sentencia negativa a la normativa general.

La gratuidad del proceso, o más bien, el cuidar "tanto como sea posible [...], salva la justa y digna retribución de los operadores de justicia, sea asegurada la gratuidad en el procedimiento [...]". Es la denominada gratuidad evangélica, es decir, causas tramitadas con el patrocinio ex officio, exceptuada la obligación moral para los fieles con recursos de entregar un donativo de justicia en favor de las causas de los pobres. La cuestión sobre la gratuidad puede afectar a la celeridad en la tramitación de los procesos, sobre todo en aquellos tribunales en los que supondría la supresión de todo el engorroso y largo trámite relativo al pago de las mismas. Personalmente, fundado en el derecho reconocido a todo fiel en el can. 221, preferiría que se dijera que nadie debe ser excluido por razones económicas de la posibilidad de introducir una causa de nulidad del matrimonio, si resulta que su petición tiene fundamento (can. 1676). 


\section{CONCLUSIÓN}

La reforma del proceso de nulidad hay que encuadrarla no solo en una mejor respuesta de la Iglesia a nivel de los tribunales sino, sobre todo, en el contexto de "conversión de las estructuras eclesiales", también de las estructuras jurídicas. Estoy consciente que la norma del MIDI tiene muchas potencialidades, judiciales y pastorales, que hemos de ir actuando, tanto en los Tribunales como en el contexto más amplio de la pastoral familiar de la Iglesia, con espíritu de servicio a la Iglesia y a las personas. El análisis de la nueva legislación y en las preguntas que hemos señalado nos ayuda a comprender que estamos en una fase provisional de su ejecución en espera de aclaraciones o explicaciones acerca de la realización del proceso. Será esto, junto a la praxis de los Tribunales y la jurisprudencia de la Rota Romana, las que nos ayudaran a comprender la naturaleza y el alcance de los cambios realizados. 